\title{
Schumpeterian competition and consumer networks: understanding concentration in the internet access market
}

\author{
Marcelo C. Pereira \\ University of Campinas
}

\begin{abstract}
Markets undergoing fast-paced product evolution impose a significant informational demand on consumers. They may have to decide among relatively heterogeneous offers while lacking the knowledge required for a fully assessed choice of suppliers. In this case, one important information source is the social network wherein the consumer is immersed, by means of the word-of-mouth (WoM). Beyond the pure informational role, we propose that $\mathrm{WoM}$ is a possible cause for the significant market concentration observed in at least one prominent hi-tech market, the internet access service, in which the market organization in many countries does not seem entirely explained by the existing economic literature. Applying an innovative approach, based on agent-based simulation and synthetic graph generation, we propose a model that is able to explain the connections between the inter-firm competition and the WoMinfluenced decision process of consumers. The model robustly demonstrates the relevant effects of WoM on the organization of the market in most situations. The results suggest that the competitive configuration of many other real markets could also be significantly influenced by WoM.
\end{abstract}

Keywords: market concentration, consumer behavior, social networks, word-of-mouth, internet access service, agent-based simulation.

\section{Resumo}

Mercados em rápida evolução do produto impõem uma demanda informacional significativa sobre os consumidores. Eles podem ter que decidir entre ofertas relativamente heterogêneas, mesmo sem dispor dos conhecimentos necessários para uma escolha totalmente informada dos fornecedores. Neste caso, uma fonte de informação importante é a rede social em que o consumidor está imerso, por meio do "bocaa-boca" (BaB). Para além do papel puramente informativo, propomos que o BaB é uma possível causa da significativa concentração de mercado observada em pelo menos um mercado de alta tecnologia, o serviço de acesso à Internet, no qual a organização do mercado em muitos países não parece inteiramente explicada pelo literatura econômica existente. Aplicando uma abordagem inovadora, baseada na simulação baseada em agentes e na geração de grafos sintéticos, propomos um modelo capaz de explicar as conexões entre a competição entre empresas e o processo decisório dos consumidores, influenciado pelo $\mathrm{BaB}$. O modelo demonstra de forma robusta os efeitos relevantes do $\mathrm{BaB}$ na organização do mercado na maioria das situações. Os resultados sugerem que a configuração competitiva de muitos outros mercados reais também pode ser significativamente influenciada pelo $\mathrm{BaB}$.

Palavras-chave: concentração de mercado, comportamento do consumidor, redes sociais, boca-a-boca, serviço de acesso à internet, simulação baseada em agentes.

Área ABEIN: 1.2 Competição, preços e estruturas de mercado

Classificação JEL: C63, D43, L15. 


\section{Introduction}

Anecdotal evidence coming from many domains suggests that markets where products show fast-paced introduction and change impose a significant informational demand on consumers. When choosing among a large variety of sophisticated goods and services, consumers have to decide among relatively heterogeneous offers from multiple suppliers usually lacking the knowledge and the information required for an efficient choice. In such bounded-rationality situation, some authors argue that one important support to the decisionmaking of consumers is the social network wherein they are embedded. The so-called "word-of-mouth" (WoM) - in this case, the exchange of personal (subjective) perceptions about products and suppliers - may turn into an important source of information for consumers, reducing the uncertainty associated with the acquisition of some products.

The idea that WoM is relevant for consumers and markets is definitely not new. The empirical evidence collected by the business literature regularly ranks the opinions and experiences of family, friends, and close social acquaintances as one of the top judgment drivers of individuals. This seems particularly true in the case of markets for sophisticated goods and services, where WoM influence usually is second only to price considerations. Also, its effect is predominantly of local nature, as the relevant "personal" social networks of consumers are more frequently small in size and highly clustered. In this case, a less obvious consequence of WoM is that the way the interaction among consumers occurs can directly affect information diffusion. In turn, it may even become an important driver of the dynamics of competition among suppliers and the market structure.

The main objective of this paper is to evaluate how relevant the link between WoM and inter-firm competition may be for the organization of the supply side of a market. Our working hypothesis is that the integration of a dual, co-evolutionary perspective involving both the supply and the demand sides may allow for the proper handling of the stylized facts coming from markets where WoM may be playing a role. The main intuition is that the patterns and the pace of the diffusion of the information about product perceptions inside the social network of consumers may create temporary lock-ins on products/suppliers with inferior price and quality attributes. If this is the case, WoM would drive a form of dynamic network externalities which, in turn, would improve the competitive situation of some incumbent suppliers and reduce the incentives to stronger competition and entry. The exploration of this dimension of the effects of WoM is mostly absent in both the economics and the business literature, at least in a more formal framework as proposed here. Yet, WoM may be considered as a potential mitigation mechanism to market failures originated from asymmetric information situations, so it may also turn into a relevant policy resource. Therefore, our contribution may be relevant for different areas of research and also for policy makers and regulators.

To explore the word-of-mouth hypothesis presented above, we focus our attention on hi-tech markets where the industry organization is significantly concentrated and propose a formal model to explain the possible causes. We want to test WoM as a potential driver of the observed concentration, notwithstanding the eventual concurrence of other factors. To minimally materialize the empirical grounds for the analysis, we selected one prominent case to assess our argument, the internet access (IA) market. It seems appealing, not only, because of its economic relevance - it is at the core of a fast growing US\$ $2+$ trillion/year global business and serves more than $50 \%$ of the world population (ITU 2013) - but, also, due to the intense, technology-driven, product-based competition among firms. In particular, the rivalry of IA providers has proved relatively weak in many countries, particularly when compared to similar technology-fueled industries, including other segments of the internet sector like hardware, software, and content. Based on the available literature, it is argued that the significant market concentration in such markets is not entirely explained by any of the usual economic justifications - including industrial organization and Schumpeterian/evolutionary theories.

One of the problems in modeling adaptive, socially-influenced consumer behavior, on the one hand, and technology-driven, product-oriented competitive dynamics, on the other, is the difficulty on proposing an 
adequate model. Tractable analytical models usually lack the level of detail required to capture the critical variables under study here. To advance, we propose an innovative modeling approach based on agent-based simulation and synthetic pseudorandom graphs methodologies, backed by a robust sensitivity analysis framework. This allows the model to explicitly detail the critical behavioral rules of consumers and suppliers as well the interactions among and between them. IA providers compete in two dimensions: price and quality. Consumers choose based on these dimensions but are also influenced by close acquaintances' decisions. Their adaptive learning is dynamically performed inside a synthetic complex network, generated in a way to reproduce multiple metrics coming from real social networks. The model parameters are calibrated using empirical data whenever possible, including the synthetic social networks.

The model results closely reproduce the microeconomic evidence coming from the internet access business worldwide and brings light to the effect of consumer networks in the organization of this class of market in general. The systemic mechanisms unveiled by the analysis were significantly dependent on the consumers' personal interactions, even when they proportionally represent a small factor in the purchase decision process. The presence of the social network induced emergent properties which simultaneously reduced the aggressiveness of competition and reshaped the user preferences beyond simple price/quality maximizing considerations. The simulation outcomes validate the unequivocal effects of WoM on the supply side and in the industry organization. In particular, they suggest that the configuration of some real industries may be unlikely without the contribution of WoM. Yet, some of the usual explanations for the industry organization were also identified as important drivers of the observed outcomes in the model, nonetheless with insufficient power to fully explain the empirical evidence.

The paper is organized in four sections, plus this introduction and some concluding remarks. The first section briefly discusses some of the most relevant approaches in economics that deal with our subject and presents the theoretical roots of the proposed model. The second section shows the data coming from the internet access market and proposes some stylized facts to summarize it. The third section describes the model and its configuration. The last section analyzes the main results and evaluates their robustness.

\section{Theoretical background}

The interaction between producers and consumers of goods and services in competitive markets has been an important focus of economics since its inception. However, from the classical authors, the analysis focused mainly on the supply side - the organization of the producers and the associated processes - as the main element of market dynamics. Proportionally, the economic literature that gives relevance to the structural properties of the buyers - the demand side - is far less rich, especially in the case of final consumer markets (individuals and families). Among the distinct thought schools, studies on the operation of markets more regularly considered consumers as homogeneous, atomized and relatively passive. While this approach may be appropriate in several situations, it is reasonable to assume that it is insufficient to explain all real markets. In particular, this seems to be the case of markets for sophisticated, technologically-innovative goods and services. Here, the high degree of novelty and technical complexity induces the scarcity of objective references for consumers to form preferences, at least in the short term. This situation increases the uncertainty associated with the purchase of such products. References about the uncertainty faced by consumers related to the plethora of new goods and services available in contemporary markets, including the internet, are plentiful (e.g., Birke and Swann 2006, Doyle 2007, Yang et al. 2007, Dasgupta et al. 2008, Dierkes et al. 2011).

Our main hypothesis is that agents may employ complementary mechanisms to define their preferences, in order to mitigate the uncertainty of the transactions they perform under imperfect information about the (potentially) desired goods and services. Among the candidate mechanisms, one often cited is the interaction with other consumers - the familiar word-of-mouth (WoM). The idea that agents may resort to informal conventions in situations where uncertainty prevents strictly rational decisions, as is the case of WoM, is certainly not new. As DiMaggio and Powell (1983) pointed, conventions and institutions have a role in the 
economy beyond the usual normative and regulatory functions. Accordingly, a cultural-cognitive dimension may be also critical to understand economic behavior (Tolbert and Zucker 1996). Socially shared mental models - of a product quality, for instance - provide the cognitive elements required by agents to make sense of the actions of other actors with whom they interact, including the suppliers in a market transaction (Denzau and North 1994). This is particularly critical when one cannot assume "well defined" (exogenous) preferences among the goods/services available because there is simply not enough information to choose à la Stigler and Becker (1977). In consequence, when the complete information assumption is unfulfilled it becomes unreasonable to expect well defined or even stable preferences. Therefore, the uncertainty associated with new or complex, hard-to-evaluate products stimulates consumers to develop alternative, nonprice strategies for choosing. Consequently, preferences can no longer be treated separately from the market exchange process (Orléan 2003). ${ }^{1}$ The information about prices and quantities is not anymore sufficient to fully orientate buyers' choices and, therefore, learning processes which are exogenous to the market transaction must intervene (Beckert 2009). As an experienced market research professional puts it, it is only "[a]fter the person acquires knowledge [about the good or service], [that] the cost-benefit becomes decisive [for choice]" (Scheller 2012). Among those knowledge-gathering mechanisms, it seems reasonable that information on the past experiences of agent's acquaintances is likely useful to assess her own preferences (DiMaggio and Louch 1998).

For a long time, most marketing scholars agreed on the importance of word-of-mouth in the markets. In the business literature, WoM is associated to interpersonal, informal communication about goods or services (Godes and Mayzlin 2004) and, overall, it is considered to have substantial impact in the marketplace (for recent overviews, see Kozinets et al. 2010 and Breazeale 2009). In particular, the positive and negative effects of WoM on the consumer purchase decisions seem consolidated in the literature (e.g., Maxham 2001), even if there is some debate about how and when the information individuals acquire from WoM is effectively employed (Sweeneyet al. 2008). It seems also established in the literature the importance of the reliability of information sources - and thus social proximity and the strength of ties - both for the consumer's decision-making as to the spread of new products (De Matos and Rossi 2008, Martin and Lueg 2013). In addition, social networks are frequently considered a suitable environment for the study of WoM, in both the consumer decision process and the dynamics of social "contagion" (Doyle 2007, Rogers 2010). Powell and Smith-Doerr (2004) and Saviotti (2009) extended the theoretical framework on how networks influence economic life and the role of the agent's ties in the acquisition and the dissemination of knowledge. In economics, however, this is a subject of more recent, despite increasing, interest (see, e.g., Campbell 2013).

From a Schumpeterian perspective, it is widely assumed that the generation of innovations is often the driver of industrial sectors involved in technology-driven product markets - the so-called technology push scenario $^{2}$ (Dosi 1982). Theory usually associates such markets with dynamic (supply side) competition, at least in their initial periods, due to high technological opportunities allied with reduced barriers to entry and fast-growing demand (Dosi 1984, Breschi et al. 2000). Some authors propose terms like "Schumpeter Mark I Regime" or "Schumpeterian competition" to describe this situation (Pavitt 1984, Dosi and Nelson 2010). However, this general perspective needs to be better qualified in some technologically-dynamic emerging markets, like the internet access, where frequently competition is weak and concentration is high.

\footnotetext{
${ }^{1}$ It should be noted that the uncertainty mitigation problem may be particularly critical in the case of services and goods in which quality - or even usefulness - is not fully defined ex ante. It is an extension to the traditional case of asymmetric information (Akerlof 1970), when quality is not known by one of the transacting parties. In the current case, quality is potentially unknowable a priori to both parties involved in the transaction, because of the impact of the transaction itself over the attributes of the transacted product, as presented later. Of course, this situation does not preclude the simultaneous presence of some level of asymmetric information.

${ }^{2}$ In contrast to the demand pull market development, in which the (known) preferences of consumers guide the technological development.
} 
There are at least three streams in the literature to explain why "imperfect" competition develops in markets like the internet access (IA). First, there is a large tradition of investigating competition in (among others) the telecommunications and the internet markets by the application of mainstream industrial organization tools: barriers to entry, network externalities, game-theoretic strategic competition, incentivesbased regulation etc. (Laffont et al. 1998, Shy 2001, Varian 2002, Laffont et al. 2003, Viscusi et al. 2005). Second, other works point to the relevance of innovation processes and formal institutions to the development of markets for internet goods and services (Davies 1996, Kavassalis et al. 1996, Corrocher 2001, Edquist 2004). Third, more recent efforts further advanced the analysis of internet markets, often sharing some analytical roots with the previous authors, more frequently exploring the sectoral dynamics from a supply side perspective (Funk 2008, Greenstein 2010, Pereira and Ribeiro 2011, Besen and Israel 2012).

Conversely, to the best of our knowledge, not many authors have considered the importance of the demand side processes for the supply side organization in cases comparable to the IA market. Although consumers of sophisticated products and services are frequently recognized as an important part of the markets, most analyses and models simply treat them as a rather static and homogeneous group of atomized individuals (e.g., among many, Schmidt and Missler-Behr 2010). Even when (somewhat) heterogeneous consumers are considered in the proposed models, the results produced by very simple interaction topologies cannot be extended to networks more similar to the actual social engagements (Goyal 2007). Therefore, we believe that the investigation of the effects of the demand organization on the market structure should consistently consider the consumer heterogeneity and the institutional setup behind the market interactions. Following Nelson (1995), we suggest that the theoretical framework required for this kind of investigation must be based on technological and institutional analytical vectors. This co-evolutionary approach is frequently proposed by authors from both the Schumpeterian and the institutional traditions (Hodgson 1988, Nelson and Sampat 2001, Fligstein and Dauter 2007) and seems appropriate for the present analysis.

As a last remark, the proposed (demand side-oriented) investigation of the industry organization does not deny the operation of the usual causal mechanisms already explored in the literature. We suggest that the potential effect of consumers' networks is mainly complementary. Supply side phenomena, like scale and scope advantages and network externalities, are likely relevant as the literature indicates (e.g., Shapiro and Varian 1999). However, we suggest that they may be not sufficiently powerful to explain the industry organization in some cases.

\section{Empirical evidence}

Our main objective is to contribute to the understanding of the impact, on the competition between producers, of consumers interacting within social networks for industries under strong innovation dynamics. To avoid addressing the issue in an abstract form, we analyze the internet access service (IA) market in which the WoM phenomenon is likely present.

Despite the market vigorous technological dynamism and the broad regulatory liberalization since its inception, the competition in the provision of internet access services (IA) has been modest in most (but not all) countries. Figure 1 presents the Herfindahl-Hirschman index (HHI), a usual measure of market concentration, for the mobile (wireless) broadband part of the IA market in selected countries. ${ }^{3}$ The high level of concentration, usually far above the conventional level of $0.15^{4}$, is evident. When evaluating the evolution of the concentration of the supply in the largest markets over time, ${ }^{5}$ one notices a slow but steady

\footnotetext{
${ }^{3}$ Similar broad figures for the fixed (wireline) IA market are not available but evidence from several countries (OOKLA 2014) seems to indicate comparable levels/diversification of concentration. Anyway, mobile access is the dominant and the fastest growing form of internet access, in both number of users and revenues.

${ }^{4}$ The US Department of Justice (2015) classifies markets with HHI between 0.15 and 0.25 as "moderately concentrated" and, when above the latter mark, as "highly concentrated".

${ }^{5}$ Measured by the number of accesses to the site speedtest.net kept by OOKLA.
} 
decrease in the fixed broadband segment. However, this reduction is partially offset by the growth in the share of mobile access, which usually shows a higher concentration. This explains the relatively stable (weighted average) levels of the aggregated HHI verified in many countries (OOKLA 2014).

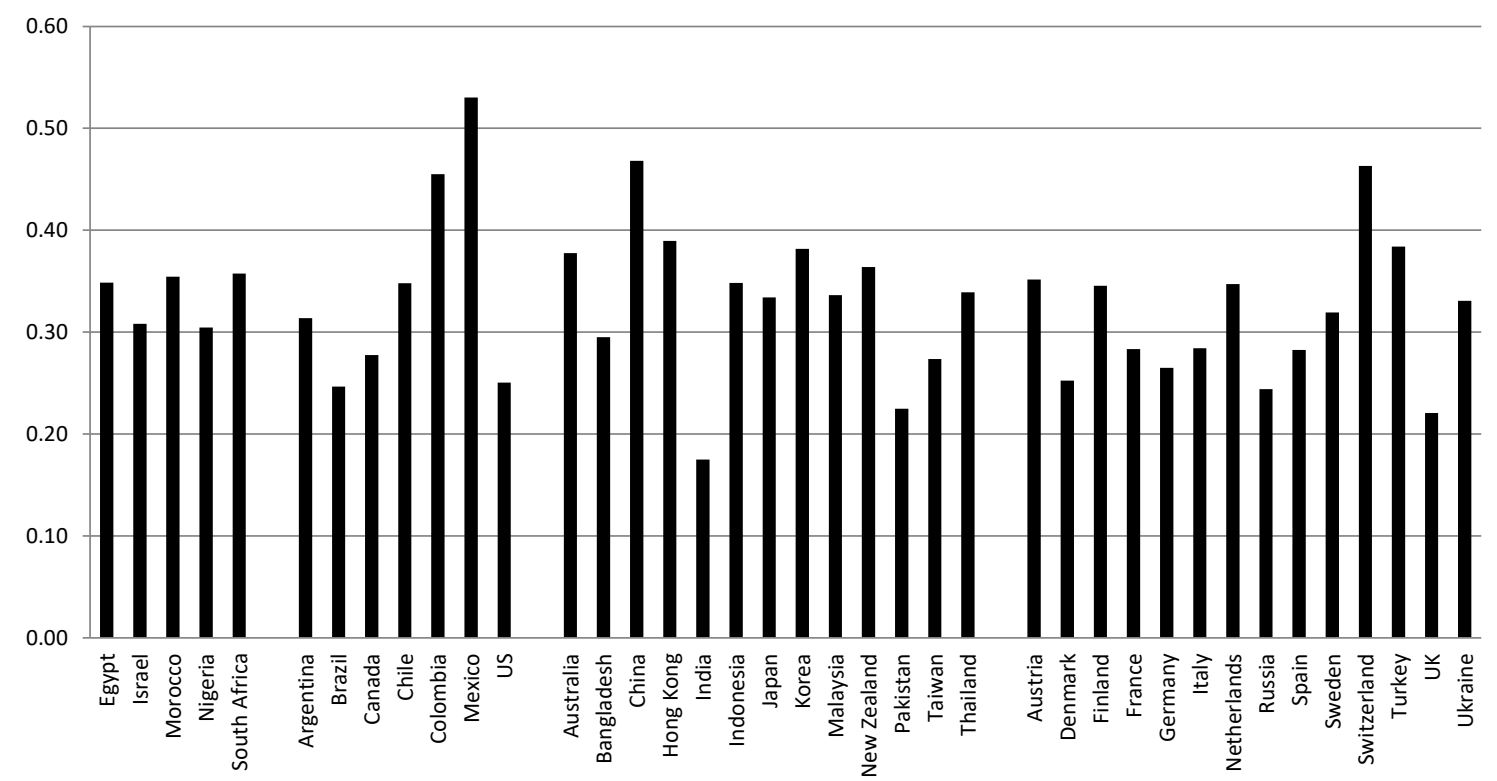

Figure 1 - Inverse Herfindahl-Hirschman index for mobile access service (2013).

Source: author's analysis based on ITU (2014), OECD (2015), regulators reports and operators public financial statements.

To help understand the issue of obtaining the appropriate information for the selection of an IA service provider by the consumer, we cite a survey ${ }^{6}$ by equipment producer Nokia Siemens (2013). It found that, among users of mobile access, the main reason for replacing providers - the churning - was service quality, even before cost considerations. The assessment revealed that, as consumers adopt IA over a longer period, quality is the most relevant subject in the decision to choose (or abandon) a supplier. Another survey by consultancy firm Analysis Mason (2013) also showed that the top reason for consumer dissatisfaction was service quality, for fixed and mobile accesses. In the same vein, a third study, ${ }^{7}$ by Ovum Consulting (2014), confirmed that broadband quality is the leading issue among mobile service consumers. A fourth survey, ${ }^{8}$ conducted by CVA Solutions (FSP 2013), indicated that $73 \%$ of the fixed and $69 \%$ of the mobile IA consumers intended to change providers in the short term (up to 12 months). In the same study, mobile and fixed access services obtained the worst results among the 38 sectors assessed (goods and services to final consumers).

The dismal IA user satisfaction figures, reflecting a clear mismatch between consumers' demands and the offers from suppliers, can be summarized in Figure 2. It shows one of the main consequences of this dissatisfaction, the very high churn. ${ }^{9}$ The global monthly rate of $3.6 \%{ }^{10}$ means that, on average, over $40 \%$ of world mobile access consumers exchange providers yearly. This number has grown in recent years. Overall, only $24 \%$ of users are satisfied with the current mobile provider (Nokia Siemens 2013) while $14 \%$ were evaluating the change of the supplier of fixed IA in the next six months, compared to $23 \%$ of mobile users

\footnotetext{
${ }^{6}$ 8,700 respondents in Denmark, South Korea, Japan, United Kingdom, United States, Brazil, Colombia, Russia (Moscow only) and India.

${ }^{7} 15,000$ consumers and 2,700 companies in the 15 largest mobile country markets.

${ }^{8} 6,000$ respondents in Brazil only.

${ }^{9}$ The churn measures the fraction of the users that leaves the base of a provider in a given period.

${ }^{10}$ Monthly weighted average for 2013 in selected 25 major national markets (listed in Figure 2).
} 
(Analysis Mason 2013). It seems evident that the task of deciding with which access provider to hire service is definitely not an easy one, despite quite common and important, and subject to elevated risk of error.

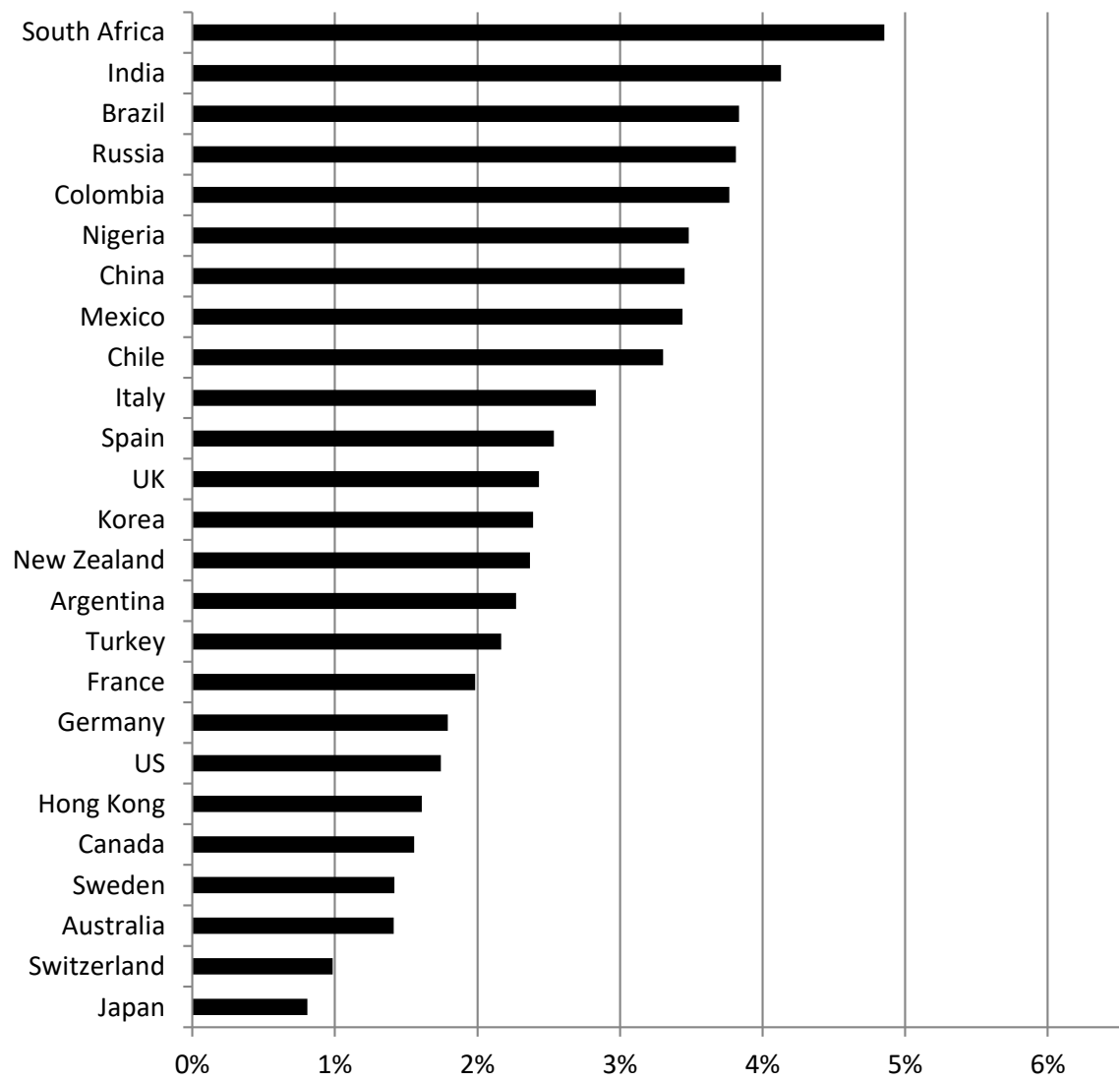

Figure 2 - Average monthly churn rate for mobile access (2013).

Source: author's analysis based on ITU (2014), OECD (2015), regulators reports and operators public financial statements.

Objectively measuring the direct effects of word-of-mouth in markets is a long time problem (Martin and Lueg 2013). On top of that, anecdotal evidence suggests that some particular cultural and institutional circumstances of countries/regions may strengthen the influence of WoM and the social network in the hiring decision. A survey from advertising agency DraftFCB (Scheller 2012) in five countries showed that more than $40 \%$ of consumers in China, India and Brazil usually receive the influence of their close social network when deciding the purchase of (any) goods and services, over 29\% in the United States and only $15 \%$ in Germany. Dasgupta et al. (2008) and Dierkes et al. (2011) used massive databases of mobile phone call information to identify the role of interpersonal relationships. They discovered that the loyalty of customers to the access provider strongly depends on the behavior and the number of their acquaintances. The second group of authors also found a significant presence of cross-buying among interconnected consumers. This influence was identified with the diffusion process within their individual social networks. The weights of the connections (measured by the frequency and the duration of calls between individuals) were decisive for the dynamics of churn and cross-buy figures. Using a Markov network model, the effect of the social network explained $19.5 \%$ of the churn and $8.4 \%$ of cross-buy (Dierkes et al. 2011). Similar results were established in the case of online social network services (Karnstedt et al. 2010, Kawale et al. 2009). In this direction, Doyle (2007) presented data indicating that in the United States $76 \%$ of consumers of certain (more expensive) goods and services consult friends before deciding on the purchase of such items. Friends were the main source of information for decision-making, ahead of previous experiences with the companies/brands $(68 \%)$, media recommendations (22\%), advertising (15\%) and internet sites (8\%). 
In the same vein, Bhatt et al. (2010) studied the acquisition of paid services within large instant message networks. Again, the authors found an elevated correlation between the adoption of products and the social proximity of adopters (cross-buy). Surprisingly, there was little evidence on the influence of very connected individuals (the high degree nodes) but, instead, a rather strong indication that the peer pressure was a more relevant force for adoption. Finally, Yang et al. (2007) presented data on the effect of the individual's social group in the decision to purchase mobile phones in the United States and China. In the study, the possible interpersonal guidance was evaluated at different levels (informational, utility and valuation) and was statistically significant in both countries. Among the levels of influence, the informational type had the greatest impact on consumer choice. Despite the cultural differences, the results were quite similar across countries and different reference groups (gender, age, profession). However, it should be noted that the social effect was not as important as the price or the design/technology in determining the purchase, indicating the competition between the classical decision criteria and the socially-influenced ones.

\section{The model}

The industrial research literature in economics often employs substantially distinct methodologies: strictly "appreciative" case studies or extremely stylized mathematical modeling. Our proposal adopts a middle ground, seeking to preserve part of the wealth of details of appreciative analysis while maintaining quantitative rigor in the treatment of links between the elements in action. Specifically, agent-based computer simulation associated with calibrated pseudorandom graphs is adopted for modeling a market where consumers are embedded in a complex social network. The proposed model is not intended to precisely replicate all the historical details of the internet sector at the level of quantitative empirical data but, mainly, to reproduce the sectoral development and stylized facts. This option also favors the construction of a relatively parsimonious model in terms of tuning elements.

The model builds on the model of the internet access market developed by Pereira and Dequech (2015), by extending the demand side to include a heterogeneous network of consumers. ${ }^{11}$ Below we present in details these extensions. The model is represented by a set of difference equations in discrete time and each simulation run ${ }^{12}$ is defined by the set of time series for all state variables. The simulation is time driven and all contemporaneous events are supposed to take place simultaneously at each time step $t=1,2,3, \ldots, 250$. One time step is roughly equivalent to three months in real calendar time. Most of the model's parameters and initial conditions were set using OECD and some other countries data as a reference, as a complete dataset from a single national market is not currently available for the model calibration. However, despite the heterogeneity in the selected group of countries, the existing matching IA market data is reasonably homogeneous among them. Therefore, we believe the adopted values are sufficiently representative for the current investigation. To control the level of bias introduced by this assumption, a rigorous sensitivity analysis of the model to all parameters and initial values is proposed in the next section.

There are two sets of agents in the model: internet access service (IA) consumers and providers (both incumbents and entrants). The model simulates the interactions among these sets of agents with heterogeneous attributes. ${ }^{13}$ The agents handle different entities in the model: technologies (generations of capital equipment to build the physical service networks), capital equipment (the service networks owned by the providers), IA service offers (set by providers and hired by consumers) and social networks (formed by consumers). The timeline of events in each time step is: (i) a single network equipment vendor performs technology search, trying to increase the productivity of existing equipment vintages and, eventually,

\footnotetext{
${ }^{11}$ The model, the presented configurations and the required scripts for the analysis of the results are available for download at http://github.com/XXXXXXX/YYYYYYY.

12 The model was coded in C++ using the Laboratory for Simulation Development (LSD), created by Marco Valente (2014), and all data analysis was done in R (R Core Team 2016).

${ }^{13}$ The number of both types of agents is not fixed, being driven by the synthetic graph generator limits and the simulation run time development, potentially reaching several thousand consumers and a few dozen providers.
} 
launching new, substantially more productive technology generations; (ii) bankrupt or too small providers leave the market; (iii) prospective entrant providers evaluate the convenience (profitability and demand opportunity) of entry and select initial network capacity (capital); (iv) providers define offers prices and network investments for the period, given the (myopic) expectations of change in the number of consumers; (v) over time, new consumers come to the market and search for a provider, considering both price and expected quality, subject to their budgets and under the influence of the social network; (vi) periodically, existing users assess the opportunity of replacing their suppliers, considering switching costs/benefits, expected quality and the social influence. ${ }^{14}$

The key transaction in the model is the selling (by providers) and the buying (by consumers) of internet access service. This sell-buy operation is of a particular kind because the quality of the product is only defined after the transaction takes place - in the model and in reality. Ex ante, quality is just an expectation to both consumers and suppliers, even if the latter are potentially better informed. This is due to technical and institutional reasons. A typical internet user drives data - in and out of the hired access network - during a small fraction of the time the service is available. For each individual user, most of the time there is no data to be transported. Given that all users of a single provider (to some extent) share the same network, it makes sense to dimension it according to the expected joint data traffic distribution, in order to avoid (potentially huge) idle capacity. This strategy significantly reduces the required resources, in average, to service each user because several can share the same facilities simultaneously. Shared networks cut costs by orders of magnitude when compared to dedicated ones. The main issue is how to guarantee the quality levels in a shared scenario under non-discrimination regulations. ${ }^{15}$ Since networks are planned and built long before consumers effectively contract services, providers have to plan ahead assuming the expected number of customers and their usage profile. Of course, this strategy is based on an adaptive learning process where errors are unavoidable. If providers "overbuild" capacity, the quality perceived by the users tends to improve somewhat in comparison to the (planned) "good" quality standard but at a higher cost. On the other hand, if they "underbuild", quality will sharply diminish - as traffic above the planned level congests the shared facilities in a markedly nonlinear way.

In the model, as a simplification, we suppose that consumers have a fixed notional traffic profile, that is, a certain required bandwidth that is fixed and the same to all consumers in a given time step $t$ (but may still grow over time). We also assume that each provider has only one type of service, meaning all of its users experience the same quality level. Therefore, the quality of each firm depends on how effective demand compares to the network capacity actually installed (the total bandwidth supported by provider $i$ in $t$ ). We thus define the ex post effective quality level $M_{t}^{i}$ offered by the provider $i$ to all its users in period $t$ as $^{16}$

$$
M_{t}^{i}=\left(\frac{\bar{Q}_{t}^{i}}{Q_{t}^{i}}\right)^{q}, \quad 0<q \leq 1
$$

$M_{t}^{i}$ is inversely proportional to the current number of customers $Q_{t}^{i}$ served by provider $i$ and directly related to the installed capacity $\bar{Q}_{t}^{i}$ of its network in the same period. $q$ is a fixed parameter that accounts for the nonlinearity between capacity mismatch and quality as perceived by the consumers (their "acuity"). Conventionally, each provider plans its network to provide the notional quality level $M_{t}^{i}=1$. Of course, this value is achieved only if the real number of customers matches the expected quantity. Here, we assume that the unit used for network capacity measurement is the number of "average users" it can support under the

\footnotetext{
${ }^{14}$ Of course, this is a simplification, as in reality the consumer also considers other attributes when choosing providers (voice and TV services for instance). However, the importance of the access is growing quickly.

15 In most countries, providers of "public interest" services like internet access are forbidden to refuse willing customers or discriminate them in terms of prices or other conditions for the provision of the services.

${ }^{16}$ In what follows, the subscript $t$ represents the $t$-th simulation time step, the superscript $i$ represents the $i$-th provider, $j$, the $j$-th technology generation, and $k$, the $k$-th user.
} 
(notional) standard level of quality. The capital equipment vendor designs one unit of network physical capacity (capital) in order to exactly meet the demand from one consumer under the standard quality level.

The population set $V=\{1, \ldots, k, \ldots$, pop $\max \}$ composes the nodes (vertices) of a graph $G=(V, E)$ where $E$ is the set of social links (edges) between them and the parameter pop $_{\max }$ is the number of potential consumers, so the social network can be represented by an undirected and unweighted graph. Or, equivalently, by the graph $G=(V, \boldsymbol{e})$ where $\boldsymbol{e}=\left[e_{k l}\right], k \neq l$ is the $p o p_{\max } \times p o p_{\max }$ adjacency matrix, listing which vertices (potential consumers) $k$ and $l$ are connected (have relationship therewith) when $e_{k l}=$ 1 , or not, if $e_{k l}=0$. Because there is no available empirical microdata on directly equivalent consumer networks, we opted for the generation of synthetic networks (or pseudorandom graphs) calibrated using information from a real social network. ${ }^{17}$ Thus, it is possible the application of appropriate algorithms for the creation of (several) pseudorandom graphs that closely reproduce the statistics of the original network (Albert and Barabási 2002, Dorogovtsev and Mendes 2002). Among the many options assessed, the 2.5KGraphs algorithm ${ }^{18}$ proposed by Gjoka et al. (2013) was selected. ${ }^{19}$ The social network structure (the adjacency matrix $\boldsymbol{e}$ ) remains constant throughout the simulation.

Demand is modeled assuming that individuals become consumers over time. The growth in the number of potential consumers happens among the members of the fixed population in $G=(V, \boldsymbol{e})$. It is modelled as a contagion process that leads to a logistic curve (Rogers 2010) and is roughly calibrated to match real data. Consumer growth reaches saturation around $t=150$. New IA consumers are heterogeneous in three dimensions: budget, preferences, and social network connections. Individual budgets are randomly (normal) distributed according to empirical evidence. They also have heterogeneous preferences (defined by the $b_{x}^{k}$ parameters, $x=1,2,3$, presented below) randomly and uniformly distributed.

Each (potential) consumer $k$ is interested in hiring internet access service for a given term $T_{c}$ (parameter). After contracting with a provider, user $k$ pays a fixed price $P_{t}^{k}$ each period for the term of the contract. Firms may adjust their prices at every time step so providers may offer different access prices to new consumers in the future $\left(P_{t+h}^{i} \gtreqless P_{t}^{i}, h=1,2, \ldots\right)$. $P_{t}^{i}$ is based on the firm $i$ desired price $\tilde{P}_{t}^{i}$ that is compatible with a given (fixed) target profitability margin on invested capital. The $P_{t}^{i}$ effectively set by each provider depends also on its current market share rate of change $\left(\dot{s}_{t}^{i}\right)$ and the expected unit cost. In a "tâtonnement" process, the firm gradually increases $P_{t}^{i}$ while it is below the desired price $\tilde{P}_{t}^{i}$ and market share is increasing $\left(\dot{s}_{t}^{i}>0\right)$. When losing market share $\left(\dot{s}_{t}^{i}<0\right)$ and its price is above unit cost $\left(\bar{c}_{t}^{e, i}\right)$ the firm gradually reduces price $P_{t}^{i}$. Otherwise, the price is kept constant. ${ }^{20}$

Every time step a new consumer $k$ arrives in the market, or an old contract expires, she ranks all IA providers according to a CES Cobb-Douglas ${ }^{21}$ expected utility function $\widetilde{U}_{t}^{i, k}$ and selects the provider with the highest expected utility considering her budget $B_{t}^{k}$.

$$
\widetilde{U}_{t}^{i, k}=\left(\frac{\bar{P}_{t-1}}{P_{t}^{i}}\right)^{\tilde{b}_{1}^{k}}\left(\widetilde{M}_{t-1}^{i, k}\right)^{\tilde{b}_{2}^{k}}\left(0.5+s_{t-1}^{i, k}\right)^{\tilde{b}_{3}^{k}}
$$

\footnotetext{
${ }^{17}$ The generated graphs represent "synthetic" social networks, similar to the real ones from which the parameters were obtained, being pseudorandom only in their non-structural properties (see next note).

${ }^{18}$ As the name 2.5K indicates (Mahadevan et al. 2006) the algorithm simultaneously reproduce the joint degree distribution of pairs of nodes $(2 \mathrm{~K})$ and the average degree-dependent clustering coefficient of the network $(0.5 \mathrm{~K})$.

${ }^{19}$ Other promising alternatives were discarded because of the inferior capability in simultaneously reproduce network parameters or due to the algorithmic inefficiency.

${ }^{20}$ The equations describing this and the remaining key model mechanisms are presented in Pereira and Dequech (2015).

${ }^{21}$ Other functional forms were evaluated for the utility function, in particular lexicographic preferences (Valente, 2012) and errorcorrecting social learning (where the information coming from the social network is applied to reduce the quality expectation error of the consumer). In the first case the model results were not significantly different, so we opted for the simpler formulation. In the second alternative, relevant different results are produced only if we assume non-systematic (zero average) errors by users, an inadequate premise in this case.
} 


$$
\begin{gathered}
\tilde{b}_{1}^{k}=\rho_{t} b_{1}^{k}, \quad \tilde{b}_{2}^{k}=\rho_{t} b_{2}^{k}, \quad \tilde{b}_{3}^{k}=\eta_{t} b_{3}^{k}, \\
\rho_{t}=\frac{1-\eta_{t} b_{3}^{k}}{b_{1}^{k}+b_{2}^{k}}, \quad \eta_{t}=\frac{\left|\mathrm{N}^{\text {prov }}(k, t)\right|}{\theta|\mathrm{N}(k)|} \\
P_{t}^{i}>0, \quad b_{1}^{k}+b_{2}^{k}+b_{3}^{k}=1, \quad b_{1}^{k} \geq 0, \quad b_{2}^{k} \geq 0, \quad b_{3}^{k} \geq 0
\end{gathered}
$$

Parameters $b_{1}^{k}, b_{2}^{k}$ and $b_{3}^{k}$ represent the weights the user attributes to price, quality and social influence when evaluating providers and are heterogeneous (uniformly distributed) among consumers. $P_{t}^{i}$ is the current price of provider $i$ and $\bar{P}_{t}$ is the (market share) weighted average price. $\widetilde{M}_{t}^{i, k}$ is the expected quality of provider $i$, as perceived by consumer $k . \widetilde{M}_{t}^{i, k}$ is usually different from $M_{t}^{i}$, the real quality experienced after the service is contracted. The expected quality $\widetilde{M}_{t}^{i, k}$ is derived from $M_{t-1}^{i}$ plus some white noise (zero average). Existing customers of provider $i$ are able to read $M_{t-1}^{i}$ directly (no noise), so they can form more accurate (but still myopic) expectations.

In (2), the influence of other users on consumer $k$, received through its neighborhood $\mathrm{N}(k)=$ $\left\{l: e_{k l}=1\right\}$ in the network $G=(V, \boldsymbol{e})$, takes part in the calculation of the expected utility. The main effect of the network concerns the local market share $s_{t}^{i, k}$ of each provider $i$ inside the social realm of user $k$ (the subnet $\mathrm{N}(k))$. The term $\left(0.5+s_{t-1}^{i, k}\right)^{\tilde{b}_{s}^{k}}$ models this relational influence of the consumer acquaintances' choices (the word-of-mouth effect) and represents an expected positive externality to (locally) popular providers, as the ones unknown in user $k$ neighborhood are less likely to be chosen. This bias may cause the consumer to choose a provider with inferior objective attributes (in price or quality) but more frequently adopted among known people, even in the absence of tangible benefits other than a possibly better evaluation of quality. Note that, in this case, we do not have the classical phenomenon of network externality (Shy 2001), as it is assumed that sharing the same provider with friends does not bring any service-associated advantage to the consumer. On the contrary, this preference can make the choice rest with a sub-optimal (expensive or congested) provider - one offering a subpar price/quality ratio.

Under the specification set in (2) and (3), the model allows for the inquiry of the decision process in a 3-dimensional space (price $\times$ quality $\times$ network influence). ${ }^{22}$ As $b_{1}^{k}, b_{2}^{k}$ and $b_{3}^{k}$ vary inside the unit simplex among the consumer population, some individuals may have preference for lower prices $\left(b_{1}^{k}>b_{2}^{k}, b_{3}^{k}\right)$ or for higher expected quality $\left(b_{2}^{k}>b_{1}^{k}, b_{3}^{k}\right)$ while others may value more social conformity $\left(b_{3}^{k}>b_{1}^{k}, b_{2}^{k}\right)$. Yet, some potential consumers may not hire any provider, if their budgets are inferior to the lowest price $P_{t}^{i}$ available. Parameters $b_{1}^{k}, b_{2}^{k}$ and $b_{3}^{k}$ are still "modulated" by the penetration $\eta_{t}$ of the IA service in the consumer $k$ neighboorhood $\mathrm{N}(k)$ (in (3), $|\mathrm{N}(k)|$ is the number of neighbors, $\left|\mathrm{N}^{\text {prov }}(k, t)\right|$ is the current number of neighbors already adopting IA service and $\theta$ is a parameter that models the proportion of purchase decision makers in the population). As $\tilde{b}_{1}^{k}, \tilde{b}_{2}^{k}$ and $\tilde{b}_{3}^{k}$ sum must adjust to one in (3), $b_{3}^{k}$ increases its relative weight as the IA service diffuses.

Lastly, it is important to note that in the model technical progress has distinct impacts over the agents. For the consumers it mainly produces lower prices and adequate quality levels (growing capacities) for the IA service but, as a simplification, no real product innovation. For the providers, technological innovation is represented by two types of advancements: "incremental", associated with regular but minor unit cost reductions of existing technology generations, and "radical", when new capital equipment vintages $j$ with significantly lower unit cost are (less frequently) introduced. Firms prospectively plan network capacity $\widetilde{Q}_{t}^{i}$ for $n$ periods, by setting expectations about the acquisition (or loss) of customers, that is, changes in relation

\footnotetext{
${ }^{22}$ Indeed, the second and the thirds dimensions try to capture information about the same point, the expected quality, but by different learning channels: individual/general available information (consumer past experience, specialized media, advertising etc.) vs. information carried by acquaintance's network ("what my friends do").
} 
to $Q_{t-1}^{i}$. When network investment $I_{t}^{i}$ is required $\left(\tilde{Q}_{t}^{i}>Q_{t-1}^{i}\right)$, firm $i$ acquires new equipment incorporating the latest technology. There is no substitution of capital already in place, except if equipment is at the end of economic life.

\section{Model results}

The model outcomes are qualitatively quite close to the empirical stylized facts described above. ${ }^{23} \mathrm{We}$ start this section with an overview of the results then move to the analysis of the robustness of the findings. All model results were evaluated by distribution moments estimation over observations from 50 simulation runs due to the presence of stochastic elements in the model. ${ }^{24}$ The number of runs was selected to ensure at least $\pm 5 \%$ precision of the estimated moments at $95 \%$ confidence level. The statistical distributions of most output variables were unimodal and reasonably symmetrical to justify the adoption of averages and variances as descriptive parameters of the model results. ${ }^{25}$ The model requires the setting of 42 parameters and 9 initial condition values (for lagged variables).

Table 1 - Network metrics.

\begin{tabular}{cccccccc}
\hline & Density & Diameter & $\begin{array}{c}\text { Avg. } \\
\text { Path Length }\end{array}$ & $\begin{array}{c}\text { Avg. } \\
\text { Degree }\end{array}$ & $\begin{array}{c}\text { Avg. } \\
\text { Clustering }\end{array}$ & Assortativity & $\begin{array}{c}\text { Power-law } \\
\text { exponent }\end{array}$ \\
\hline Synthetic & 0.0022 & 10.36 & 3.56 & 28.32 & 0.201 & 0.038 & 2.01 \\
\hline Facebook & 0.0071 & 13.40 & 4.80 & 25.30 & 0.171 & 0.17 & 1.50 \\
\hline
\end{tabular}

Source: average values for 50 synthetic networks vs. Facebook metrics from Wilson et al. (2009).

The calibration of the pseudorandom graph generator was done by maximum likelihood estimation using actual network microdata from Viswanath et al. (2009). ${ }^{26}$ After initial screening of potential candidates, we selected a representative sub-network of the online social network Facebook. Apart from being a network that, by construction, is created from actual networks of human social relationship, the large dimension of this network, which includes a representative sample of the US population (Gjoka et al. 2010, Sala et al. 2010, Ugander et al. 2011) was also important to ensure adequate calibration of the graph generator. Using the 2.5K-Graphs algorithm (Gjoka et al. 2013), a set of 50 calibrated and distinct networks were produced. ${ }^{27}$ As expected, the metrics of the generated networks (Table 1) were close to the ones obtained from the original Facebook network in 8 countries (Wilson et al. 2009), even after the significant downscaling (of about 1:5). Also, the main statistical distributions of some important features (for human social networks) showed compatible behavior ${ }^{28}$ For instance, the degree distribution (the number of connections that each node has the network) has the usual scale-free ("fat tail") property.

In Figure 3 the substantial churning stylized fact is clearly reproduced by the model as an emergent property - as it was not explicitly programmed. Churn around $4 \%$ per time step - with an initial growth trend

\footnotetext{
${ }^{23}$ Unfortunately, being a relatively "young" market, the IA empirical time series are still too short for a comprehensive and meaningful quantitative validation of results.

${ }^{24}$ The model runs are generated using different "seeds" for the pseudorandom number generator, assuring the absence of serial correlation in the results, including for the pseudorandom graph (the synthetic social network).

25 Also, unit roots (Augmented Dickey-Fuller, Phillips-Perron and Kwiatkowski-Phillips-Schmidt-Shin) and ergodicity tests (Kolmogorov-Smirnov, k-Sample Anderson-Darling and Wald-Wolfowitz) were performed to ensure the time series were stationary and ergodic so the distributions moments adequately represent them.

${ }^{26}$ The use of pseudorandom graphs of "high fidelity" requires the availability of representative actual samples of meaningful emulated networks to allow the statistical estimation of the large number of required parameters.

27 The "synthetic" networks were scaled down to about 13,000 nodes and 180,000 connections each, to keep computation times manageable, with no significant loss of network "fidelity" as indicated by Table 1.

${ }^{28}$ Details on all distributions are available in Pereira (2015).
} 
- are observed during the period of demand acceleration $(t<50)$. However, even after market saturation $(t>125)$, churn is still consistently high, usually above $1 \%$. Also, the narrow confidence interval - the region between the dotted lines - shows that this stylized fact is consistently reproduced in most (if not all) runs.

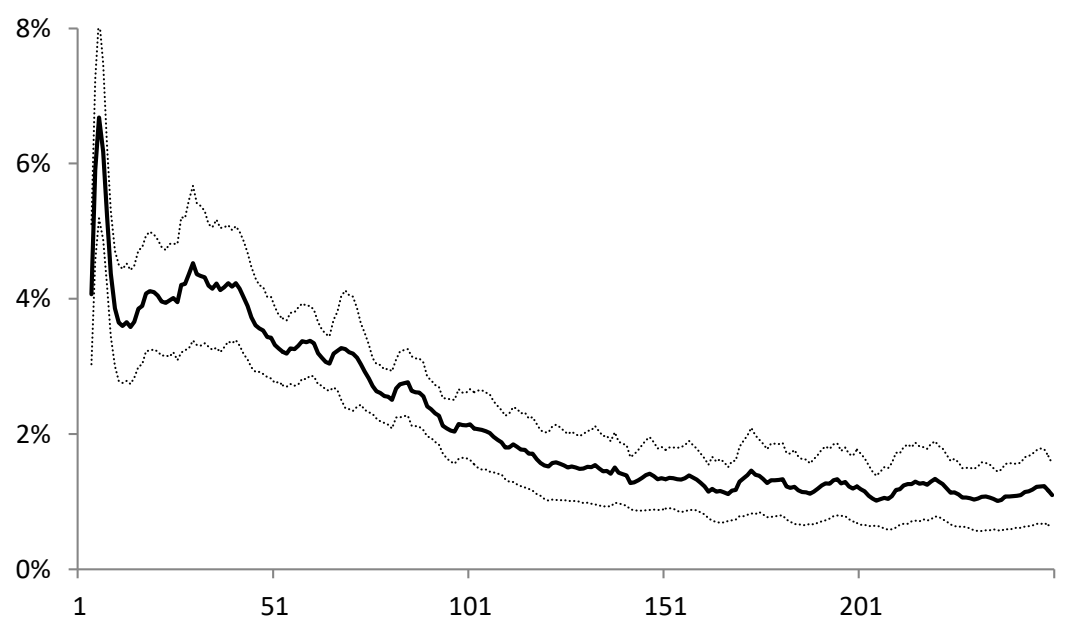

Figure 3 - Churn rate $\left(y\right.$-axis) over simulation time $(x$-axis $){ }^{29}$

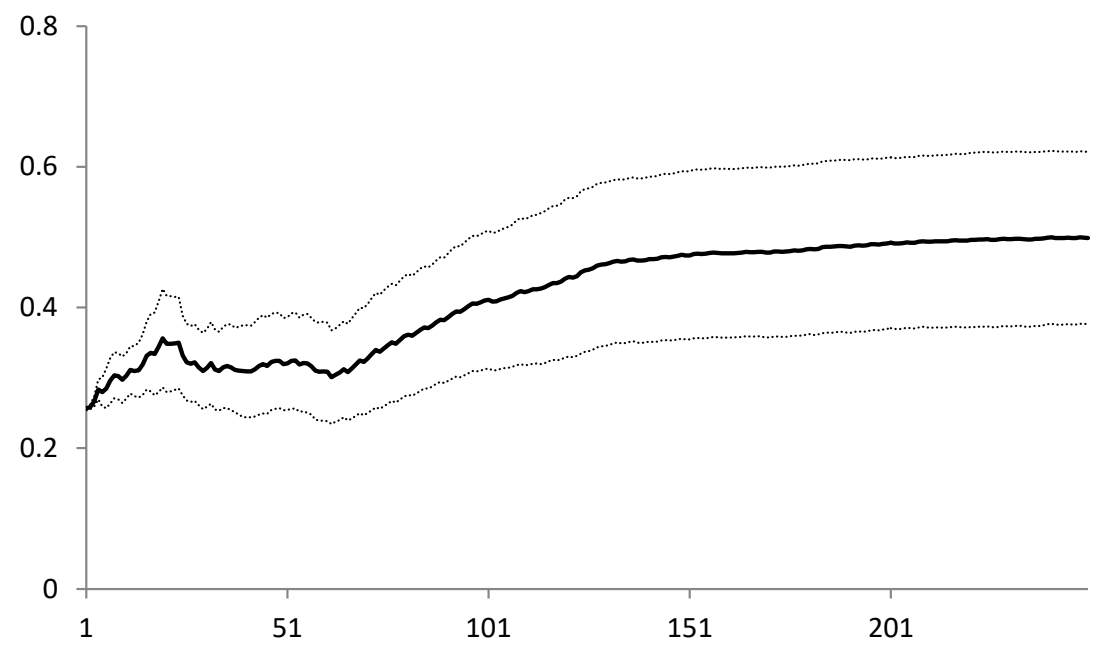

Figure 4 - Herfindahl-Hirschman index (y-axis) over simulation time (x-axis).

The overall market competition remained very limited in most simulation runs, as presented in Figure 4, with the Herfindahl-Hirschman index (HHI) for market shares stable and above 0.25 for most of the simulated time, closely replicating the high concentration stylized fact. The relatively narrow confidence band indicates that the concentration is systematically high among runs, thus not being driven by the stochastic components in the model. It should be noted that this result was obtained without enabling in the model many of the advantages usually attributed to the incumbent - the "barriers" to entry - such as economies of scope in advertising and marketing activities, synergies/complementary products etc. Economies of scale, however, are enabled, in accordance with the empirical evidence.

\footnotetext{
${ }^{29}$ In the following plots the $x$-axis represents time in simulation time units (one quarter), unless stated otherwise. The results are shown by their averages (continuous line) and the confidence intervals from multiple runs (dotted lines). Intervals have a significance level of $1 \%$ so they "enclose" the results of the vast majority of runs.
} 
Considering that the model consistently matched the proposed stylized facts, the next step is to evaluate how robust the findings are, i.e., if outcomes depend on particular configuration set-ups or, conversely, represent more general - or "structural" - properties of the model. To answer this question, an in-depth sensitivity analysis of all parameters and initial conditions (the "factors") was performed. Factors were extensively tested over the entire plausible ranges of values that are still compatible with (somewhat above) extreme empirical magnitudes. Factors without empirical references were tested over their full significant range.

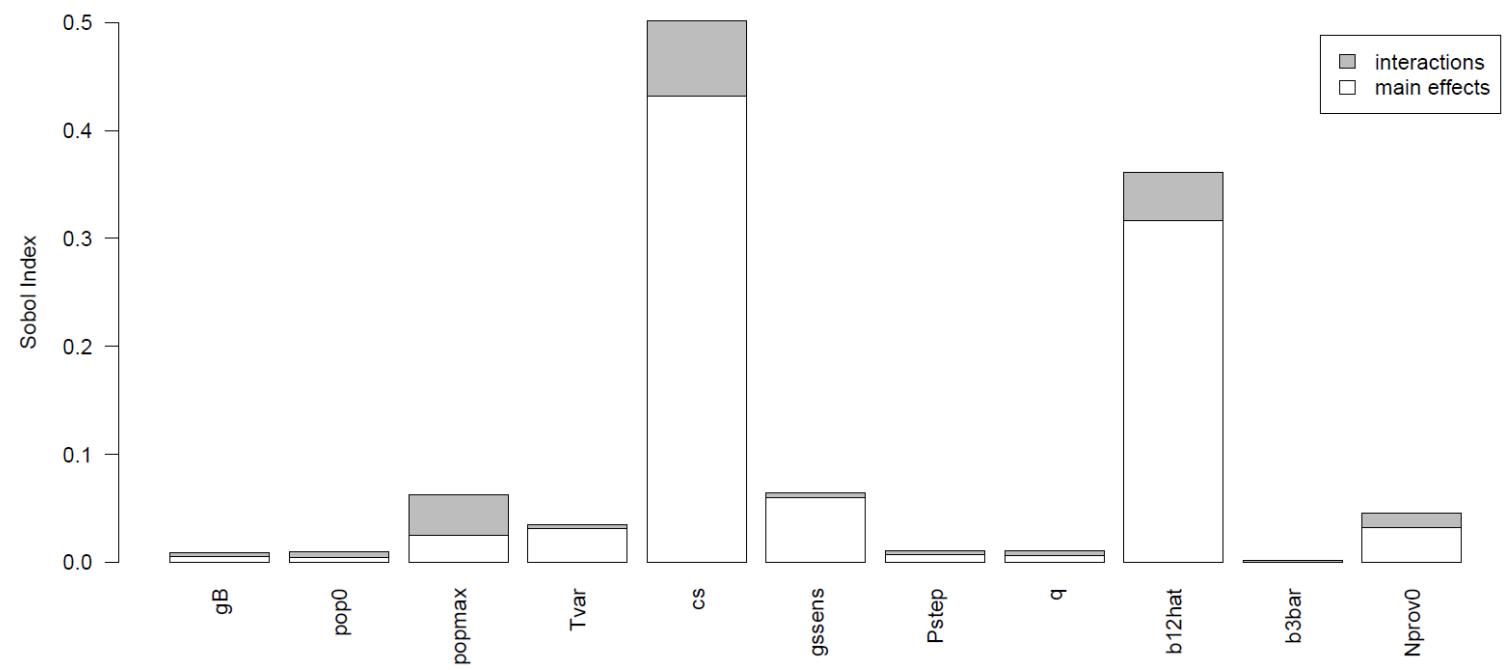

Figure 5 - Herfindahl-Hirschman index sensitivity on an 11 factors meta-model.

(The gray area in the bars indicates the part of the effect due to interactions with other factors.)

Sensitivity analysis (SA) of all factors was initially performed using the elementary effects (EE) screening technique ${ }^{30}$ (Morris 1991, Saltelli et al. 2008) on all important market indicators ${ }^{31}$. The idea, at this stage, is to identify the factors that induce significant changes in the indicators under analysis, either directly or through interaction with other factors. Not surprisingly, only a subset of the factors - less than half of them - was able to affect the model results in a quantitatively relevant level. However, the SA of simulation models cannot be fully assessed, on rigorous grounds, only by the application of "one-factor-at-a-time" procedures, like EE or ANOVA (analysis of variance), because of their characteristic nonlinearity and nonadditivity properties (Saltelli and Annoni 2010). To overcome this restriction Sobol decomposition ${ }^{32}$ (Sobol 1993, Saltelli et al. 2008) was performed to achieve a robust assessment of the quantitative impact of the factors over the selected indicators, considering the entire (global) parametric space as well nonlinearity/nonadditivity. However, due to the relatively high computational cost to produce the decomposition - several thousands of runs - a simplified version of the original simulation model - a meta-model - was specified and estimated for this purpose using Kriging (Salle and Yildizoğlu 2014). ${ }^{33}$

\footnotetext{
${ }^{30}$ Elementary effects technique proposes both a specific design of experiments, to efficiently sample the parameter space onefactor-at-a-time, and some linear regression statistics, to evaluate linear and nonlinear effects of factors on indicators. It represents a richer and more efficient alternative to traditional ANOVA tests.

${ }^{31}$ Indicators used: churning, quality index, concentration indexes (HHI, CR4), number of providers, market size, profitability, average age of firms, and weighted averages and variances of market prices.

${ }^{32}$ Sobol decomposition is a variance-based, global sensitivity analysis method consisting in the decomposition of the variance of the chosen model indicator into fractions according to the variances of the factors selected for analysis, better dealing with nonlinearities and non-additive interactions over the entire factors domains space.

${ }^{33}$ The Kriging meta-model "mimics" our original model by means of a simpler, mathematically tractable approximation. Kriging is an interpolation method that uses a machine learning method (Gaussian processes) to provide, under fairly general assumptions, the best linear unbiased predictors for the response of complex, non-linear computer simulation models. The meta-model is estimated
} 
The Sobol decomposition was performed with different meta-model specifications using the top 7, 11, 16 and 27 factors found on the EE screening. The meta-model including the 11 top factors provided the better fit to the original model (minimum RMSE and MAE) and so was selected as the base model. The global SA objectively identified the contributions of each factor to the concentration index (HHI) as presented in Figure 5. Both individually and in interaction with other factors, the parameters $c_{S}$ and $\bar{b}_{1}-\bar{b}_{3}{ }^{34}$ have the largest potential for changing the concentration levels in the simulation. In particular, the SA shows an intermediate HHI level under the model calibration values (the round dot in the plots). Thus, there is reasonable potential for variation of the HHI - positive and negative - by changing the critical parameters. This is clear in Figure 6, which indicates the (meta-model) predicted $\mathrm{HHI}$ along the entire experimental domains of these parameters. The first two plots present the individual effects and the third, the joint influence. ${ }^{35}$
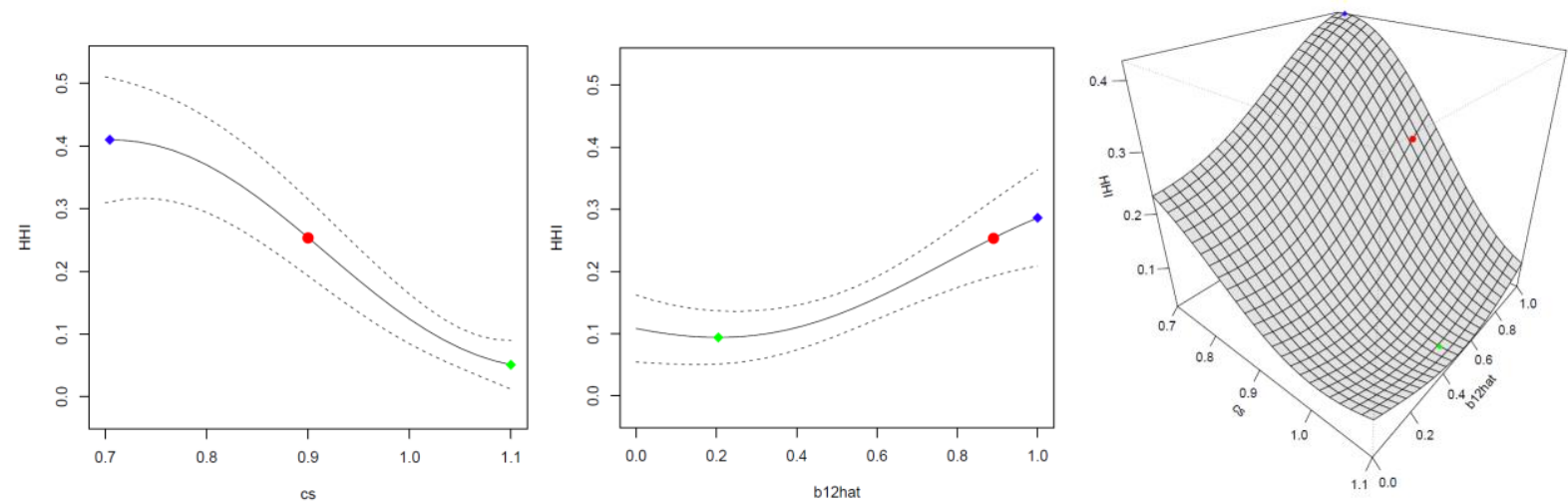

Figure 6 - Meta-model predicted Herfindahl-Hirschman index response for particular factors.

(The round dot indicates the predicted response at calibration settings, the other markers are at the maximum and minimum response values. All other factors are set at the model's calibration values.)

However, the interesting results in Figures 5 and 6 are the meta-model predictions, not the original model outcomes for those parameters configurations. They point to interesting areas of the parametric space but are only interpolations over a limited sample of the original model true response surfaces and so subject to errors. To confirm the meta-model findings, further exploration of the original model around the interesting areas was conducted for some critical sets of parameter values, in particular, the level of economies of scale $c_{S}$, the consumer budgets growth rate $g_{B}$, the quality perception nonlinearity level $q$ and the preferences weights averages $\bar{b}_{1}-\bar{b}_{3}$. In the chosen test sets, the parameters values were selected to minimize or maximize the HHI value during most of the simulation time, now in the original model. In figure 7 we present the HHI response to the three most interesting test sets. Set 1 provides the maximum (average) concentration over most of the entire period. Sets 2 and 3 produce minimum HHI in different phases of the simulation, at the beginning or at the end, respectively, and in both cases provide averages which fall below or close the conventional limits of moderate concentration (0.15). These results indicate that the high HHI level is not a structural property of the model and further research of its causes is necessary.

Using the model as an investigation device, we found that the increasing effects on HHI observed in Figure 7 were due to: (i) the rise of the economies of scale (higher $c_{S}$ ); (ii) the lack of growth in the budgets available to consumers (lower $g_{B}$ ); (iii) the reduction of the acuity of users to quality differences between

from a set of carefully picked observations from the original model using a highly efficient near-orthogonal Latin hypercube design of experiments.

${ }^{34}$ Representing, respectively, the economies of scale parameter for the providers' operating costs and the consumers' preferences sensitivity parameters to price, quality and social influence.

${ }^{35}$ Because $\bar{b}_{1}, \bar{b}_{2}$ and $\bar{b}_{3}$ are defined in the unit simplex in the figures they are represented by

$$
\hat{b}_{12}=\frac{\bar{b}_{1}}{\bar{b}_{1}+\bar{b}_{2}} \quad \text { and } \quad \bar{b}_{3}=1-\bar{b}_{1}-\bar{b}_{2}
$$


providers (lower $q$ ); and (iv) the higher influence of acquaintances $\left(\bar{b}_{3}\right)$ and of prices $\left(\bar{b}_{1}\right)$ in the consumer's utility/decision. The first two processes are expected and their action is usually considered in the literature. On the other hand, the somewhat surprising mechanisms operating in (iii) and (iv) are also important for the market concentration but are far less frequently discussed.

The lower is the accuracy with which consumers realize differences between providers' qualities (represented by parameter $q$ ), the less valuable is the expected quality as a decision-making information. If expectation error is present (as it is here), the quality evaluation by the consumer can become counterproductive (reduced discriminatory power), as at some level the "noise" in the market may surpass the weak signal she is trying to "detect". As $q$ decreases, the importance of some alternative, proxy forms of quality evaluation that is not associated to direct (technical) observation, like WoM, is reinforced. In the absence of such proxies, better services offered by entrants are not recognized by consumers, easing the defense of incumbents' market shares by means of lower prices. Indeed, the lack of effective quality proxies reinforces the benefits of economies of scale $\left(c_{s}\right)$ for the incumbents, by reducing their costs vis-à-vis the entrants and facilitating low-price strategies for them, as reflected in the model results for test set $1 .{ }^{36}$ Here, the model advances on the explanation of the mechanisms that both generate the situation on the consumer side, at first place, and propagate its consequences to the provider side of the market.

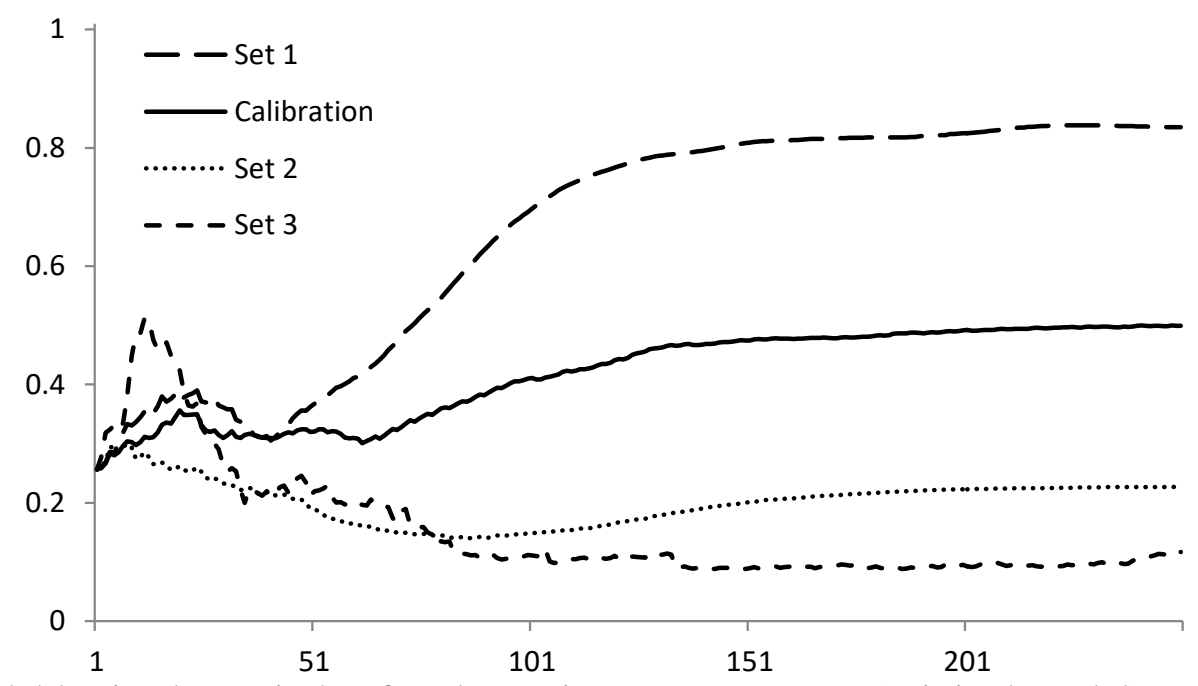

Figure 7 - Herfindahl-Hirschman index for alternative parameter sets (original model).

An even more unusual theoretical justification for market concentration is the effect induced by the feedback between collective and individual choices, at least in the scope proposed here. This issue was addressed by a few authors of empirical studies, such as David (1985), Jonard and Yildizoğlu (1998) and Birke and Swann (2006). Before them, researchers in various disciplines warned of the importance of social networks - in general - for the dissemination of new products, technologies, ideas, etc. (Rogers 2010, Dosi 1991). However, even in the modern industrial organization their role in the diagnosis of uncompetitive markets is limited to the issue of tangible network externalities (Arthur 1989, Shy 2001). This is the situation where the market movements, as a whole, signal and coordinate the optimal action of all consumers. However, this is not the case here since it is unreasonable to assume that by adopting the most "popular" supplier in their social circle the consumer could expect the kind of tangible positive payoffs proposed by the network externalities literature.

In our model, it is relevant that the significant impact of WoM on the market concentration shows up from relatively small values for $\bar{b}_{3}$, the parameter defining the intensity of the social effect on consumer

\footnotetext{
${ }^{36}$ The association of incomplete information with market failures is obviously not new. The concept has been explored from the seminal work of Akerlof (1970) but is not systematically associated with market concentration.
} 
decision. Starting from $\bar{b}_{3} \approx 0.2$ (or half of the calibration setting), over time the influence of WoM transits from significant to dominant. ${ }^{37}$ The introduction of endogenous factors in the formation of preferences, although in a minority proportion, caused an emergent phenomenon of downward causation (see Hodgson and Knudsen 2004 for another example). The process of feedback between the emerging structure, represented by the choices of a group of users in a given context and the individual decision increasingly affected the sector organization dynamics over time. This mechanism features an intrinsically different situation from the classical network externality case, as consumers do not tangibly benefit from the number of "friends" connected to the same provider's network (given the interconnection between networks). The best they may get is an intangible payoff: (i) an uncertain and biased clue about quality, and (ii) some social "comfort" when choosing under elevated uncertainty.

To further illustrate the strong effects of the social network on the industry organization, Figure 8 shows the results (50 runs averages) for different values for $\bar{b}_{1}, \bar{b}_{2}$ and $\bar{b}_{3}$ (all other parameters are kept at calibration values). Given the absence of objective empirical data to calibrate these parameters, the strategy here is to explore the entire space of parametric alternatives, taking advantage of the fact they are defined in an unit simplex $\left(\bar{b}_{1}+\bar{b}_{2}+\bar{b}_{3}=1\right)$. As a consequence, this exercise shows the required weights combinations in the consumers' utility equation (2) to produce more or less concentrated markets. In practice, it directly shows the effect of different WoM levels $\left(\bar{b}_{3}\right)$ on the industry organization $(H H I)$, taking advantage that the causation direction is known (from the demand to the supply side).

In Figure 8, the latitude of the possible consequences to the market structure is surprising. Considering first the scenarios without social influence (labeled in the format "XX-YY-00", $\bar{b}_{1}=0 . \mathrm{XX}, \bar{b}_{2}=0$. YY), the HHI results are contained in a significantly narrow $[0.05 ; 0.34]$ range (at 95\% confidence). As expected, the greater the weight of (technical) quality expectation $\left(\bar{b}_{2}\right)$ in consumer decision, as in curves "00-100-00" and "50-50-00", the more competition is encouraged, leading to HHI lower than 0.1 in the long term ${ }^{38}$ and below the conventional threshold level for significant concentration (0.15). Also along the anticipated results, if the model is set for (low) prices only $\left(\bar{b}_{1}\right)$ preferences (curve "100-00-00"), the opposite occurs: the user focus on prices only allows the major incumbents to benefit from the reduced costs provided by first-mover and scale advantage and the HHI remains above 0.3 (high concentration). More surprisingly, the neutral case of consumer "rational" preferences, when one considers a price and quality balanced mix ("50-50-00"), produces low concentration (HHI at 0.07) at odds with the empirical evidence, even under the presence of significant economies of scale.

However, in all the scenarios in which social influence $\left(\bar{b}_{3}\right)$ is above a certain threshold (labeled "XXYY-ZZ", $\bar{b}_{3}=0 . \mathrm{ZZ}$ ), the robustness of the results showing significant concentration is remarkable. For all combinations of parameters in which $\bar{b}_{3}$ is larger than values around 0.2 , the HHI exceeded the conventional concentration limits and were closer to the empirical data from most countries. As the role of WoM gets more important in the model, the expected levels of market concentration unequivocally raise. This remains true for any given ratio of the preference parameters for price and quality $\left(\bar{b}_{1} / \bar{b}_{2}\right)$, often by a wide margin. Still, one can argue that this result could be a consequence of the (arbitrary) specification adopted for the consumer choice (Eq. 2). However, further investigation showed that the continuous feedback of the social process is the determining factor for its relevance, much more important than the specification employed, ${ }^{39}$ particularly in the long run. It seems to be in action here a particular form of the phenomenon of dynamic increasing returns or lock-in (Arthur 1989). The stylized case of pure social influence (curve "00-00-100" in

\footnotetext{
37 This is the reason the Kriging meta-model (erroneously) gives relatively low importance to the value of $b_{3}$ in the prediction of the HHI: when $b_{3}$ is set above a small threshold level it induces a sharp nonlinear hysteresis effect on the HHI so the "smoothing" characteristic of the Kriging interpolation process does not model it well.

${ }^{38}$ Even under the presence of economies of scale, these scenarios provide substantially greater competitiveness to small firms, because they can focus on niches of quality-demanding consumers inaccessible to large incumbents.

${ }^{39}$ As already mentioned in Footnote 21, several experiments were made with different alternatives to the functional specification of Equation 2. Also, different social network structures were tested without qualitative changes to the outputs of the model.
} 
Figure 8), where the market quickly stabilizes after just a few consumers arrive, demonstrates the power of the social lock-in in the model.

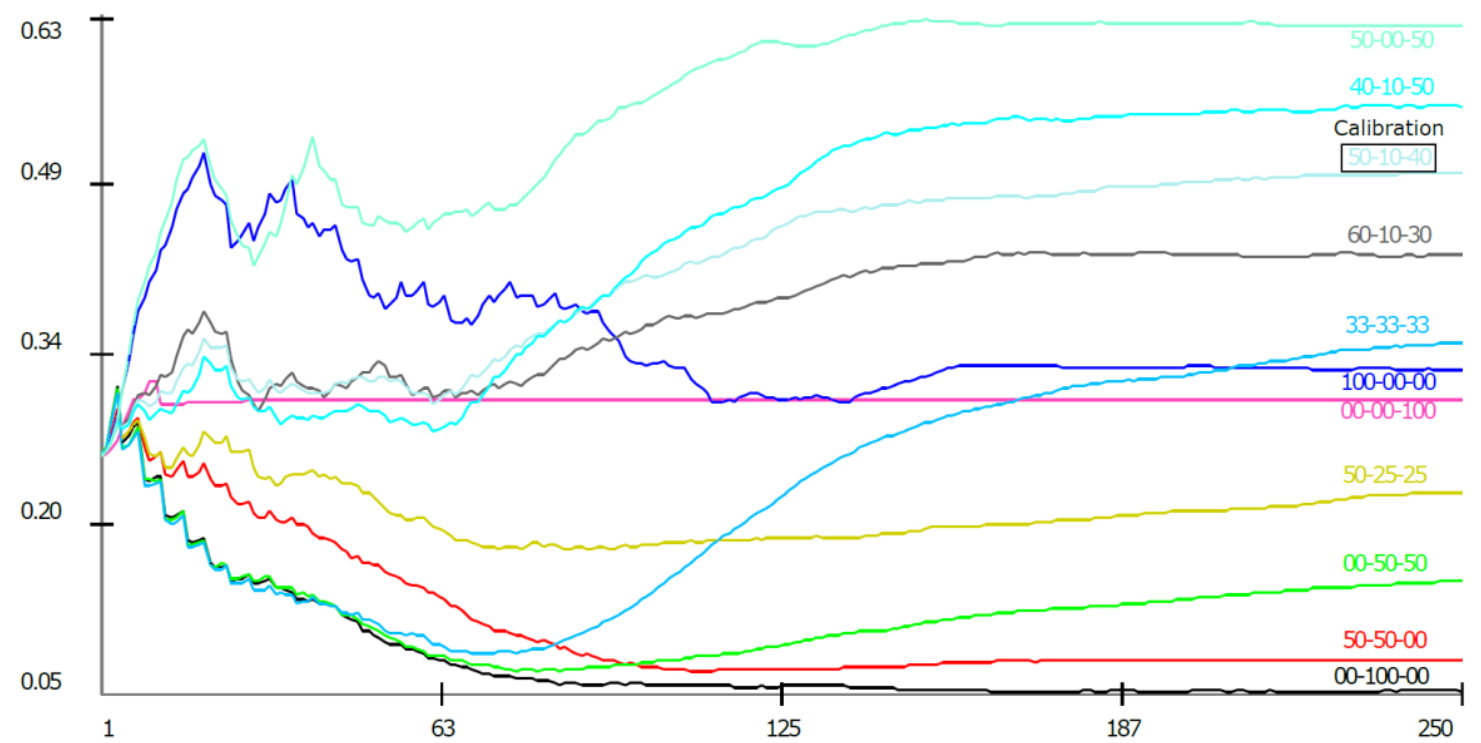

Figure 8 - Herfindahl-Hirschman index for alternative $\overline{\boldsymbol{b}}_{\mathbf{1}}-\overline{\boldsymbol{b}}_{\mathbf{2}}-\overline{\boldsymbol{b}}_{\mathbf{3}}$ parameters settings.

(Calibration setting ("50-10-40") and eleven alternative scenarios identified by the labels in the format "XX-YY-ZZ", being $\bar{b}_{1}=0 . \mathrm{XX}$ (price), $\bar{b}_{2}=0 . \mathrm{YY}$ (quality) and $\bar{b}_{3}=0 . \mathrm{ZZ}$ (social network).)

Evidently, the results above are a consequence of the assumptions made during modeling, which can lead one to question such relevance of the social network and WoM as tautological. However, this is definitely not a self-evident criticism here. The market concentration level effectively emerges in the model as a macro property originating from the interactions of many independent consumers and firms. At the firm level, the model shows the usual market turbulence, with large incumbents still shrinking and even getting out of the market over time and some entrants succeeding. The difference from a more competitive market is more subtle. The temporary lock-in inside the local acquaintances' networks introduces a bias in the success probabilities distribution among the population of firms. In other words, just being "popular" among several local peer neighborhoods is not a sufficient condition to indefinitely keep the local lock-in around a given incumbent provider. Sooner than later, an insufficiently adequate combination of price and effective quality from a "laggard" incumbent, driven by the technology dynamics, can easily move customers away and to a different lock-in state.

In summary, with the aid of the model it was possible to assess that the process of word-of-mouth inside local interaction networks is potentially more central than habitually assumed in the organization of industries. In line with the empirical evidence, the model shows that the hypothesis of the influence of the demand side set-up in the sectoral competition is logically compatible with the historical trajectory of concentration (at the macro level) of the internet access market. Thus, suggesting that without the concurrence of some demand side features a highly concentrated market structure would be far less plausible.

\section{Concluding remarks}

One of the critical benefits of computer simulation models is the possibility of experimentation with different interaction structures among agents. This allows for the analysis of issues related to the social networks in which they participate and their influence on the emerging systemic features. As shown in the paper, the proposed model enables local interaction between providers and consumers and among the latter, giving rise to a meaningful evolving complex social system that, in turn, produced interesting, surprisingly close to reality emergent properties. 
The model unequivocally demonstrated the centrality of the endogenous formation of consumer preferences for the organization of some markets. By "granting" to the acquaintances' network a "voice" in the purchase decision, even if at a modest weight, the consumer opens herself to influences that are beyond the purely informational dimension. Considering the dynamics of information diffusion within large, sparse and uneven networks, social influence brings to the analysis new and essential variables. They showed essential for the understanding of the market demand, confirming our hypothesis on the economic relevance of the word-of-mouth. In this sense, the process of endogenous preferences formation entailed by WoM was decisive for the obtained results also on de supply side. As word-of-mouth stimulated local and transitory lock-ins of consumers in certain incumbent offers, in aggregated terms it reduced the competitive advantage of higher quality entrants and increased the effectiveness of incumbents' economies of scale. Therefore, the introduction of even modest WoM shocks in consumers' preferences formation originated a phenomenon of emergent nature that was able to completely change the industry organization dynamics. At the end, it showed the potential to effectively constrain the development of Schumpeterian competition.

These are relevant results that, we believe, deserve further consideration in the studies of marketplaces, not just in economics. This includes normative issues about antitrust and market failure due to asymmetric information. Bringing the demand side to the center of the analysis, without discarding the intricacies, idiosyncrasies, and bounded-rational nature of consumers' decision making, will certainly throw light on several phenomena that are not well understood yet. Finally, those conclusions also make clear the importance of considering markets - and the whole economy - as real complex evolving systems and, so, of applying the appropriate methodological tools.

\section{References}

Akerlof, G.A. The Market for "Lemons": Quality Uncertainty and the Market Mechanism. Quarterly Journal of Economics, v. 84, n. 3, p. 488500, Aug. 1970.

Albert, R.; Barabási, A. L. Statistical mechanics of complex networks. Review of Modern Physics, v. 74, p. 47-97, 2002.

Analysis Mason. The Connected Consumer Survey 2013. Boston: Analysis Mason, $2013 . \quad$ Available at http://www.analysysmason.com/Research/Content/Reports/Connected-consumer-survey-Mar2013-RDMV0-RDMM0-RDMY0-RDMB0/. Access in 24 mar. 2014.

ANATEL (Agência Nacional de Telecomunicações). Relatório Anual 2013. Brasília: ANATEL, 2014. . Acessos SCM/SMP. 2014c. Available at http://www.anatel.gov.br. Access in 08 Nov. 2014.

Arthur, B. Competing Technologies, Increasing Returns and Lock-In by Historical Events. Economic Journal, Oxford, v. 99, n. 394, p. 116-131, 1989.

Beckert, J. The social order of markets. Theory and Society, v. 38, n. 3, p. 245-269, 2009.

Israel, M. A.; Besen, S. M. The Evolution of Internet Interconnection from Hierarchy to 'Mesh': Implications for Government Regulation. Available at SSRN 2104323, 2012.

Bhatt, R.; Chaoji, V.; Parekh, R. Predicting product adoption in large-scale social networks. ACM International Conference on Information and Knowledge Management, 19a, 2010. Proceedings... New York: ACM Press, 2010.

Birke, D.; Swann, P. Network effects and the choice of mobile phone operator. Journal of Evolutionary Economics, Heidelberg, v. 16, n. 1-2, p. 65-84, Apr. 2006.

Breazeale, M. Word of mouse: an assessment of electronic word-of-mouth research. International Journal of Marketing Research, v. 51, n. 3, p. 297-318, 2009.

Breschi, S.; Malerba, F.; Orsenigo, L. Technological regimes and Schumpeterian patterns of innovation. Economic Journal, Oxford, v. 110, n. 463, p. 388-410, Apr. 2000.

Campbell, A. Word-of-Mouth Communication and Percolation in Social Networks. American Economic Review, v. 103, n. 6, p. 2466-2498, Oct. 2013.

CETIC.BR (Centro de Estudos sobre as Tecnologias da Informação e da Comunicação). Pesquisa sobre o uso das tecnologias de informação e comunicação no Brasil: TIC Domicílios e TIC Empresas 2013. São Paulo: CGI.br, 2014.

Corrocher, N. The Internet services industry: Sectoral dynamics of innovation and production and country-specific trends in Italy and in the UK. Working Paper ESSY, 2001. Available at http://www2.cespri.unibocconi.it/essy/wp/corroch.pdf. Access on 28 Dec. 2011.

Dasgupta, K.; Singh, R.; Viswanathan, B.; Chakraborty, D.; Mukherjea, S.; Nanavati, A. A. Social ties and their relevance to churn in mobile telecom networks. In International Conference on Extending Database Technology Advances in Database Technology, $11 \mathrm{a}$, 2008. Proceedings... New York: ACM Press, 2008.

David, P. A. Clio and the Economics of QWERTY. American Economic Review, Pittsburgh, v. 75, n. 2, p. 332-337, May 1985.

Davies, A. Innovation in Large Technical Systems: The Case of Telecommunications", Industrial and Corporate Change, Oxford, v. 5, n. 4, p. 1143-1180, 1996.

de Matos, C. A.; Rossi, C. A. V. Word-of-mouth communications in marketing: a meta-analytic review of the antecedents and moderators. Journal of the Academy of Marketing Science, v. 36, n. 4, p. 578-596, Sep. 2008. 
Denzau, A.; North, D. Shared Mental Models: Ideologies and Institutions. Kyklos, Zürich, v. 47, n. 1, p. 3-31, 1994.

Dierkes, T.; Bichler, M.; Krishnan, R. Estimating the effect of word of mouth on churn and cross-buying in the mobile phone market with Markov logic networks. Decision Support Systems, v. 51, p. 361-371, 2011.

Dimaggio, P. J. Interest and agency in institutional theory. In Zucker, L. (Org.). Institutional Patterns and Organizations, Cambridge: Ballinger, 1988.

Dimaggio, P. J.; Louch, H. Socially embedded consumer transaction: For what kinds of purchases do people most often use networks?. American Sociological Review, v. 63, n. 5, p. 619-637, Oct. 1998.

Dimaggio, P. J.; Powell, W. W.. The Iron Cage Revisited: Institutional Isomorphism and Collective Rationality in Organizational Fields. American Sociological Review, v. 48, n. 2, p. 147-160, 1983.

Dorogovtsev, S. N.; Mendes, J. F. F. Evolution of networks. Advances in Physics, v. 51, p. 1079-1187, 2002.

Dosi, G. The Research on Innovation Diffusion: An Assessment. In Nakićenović N, Grübler A (Ed.). Diffusion of Technologies and Social Behavior. Berlin: Springer-Verlag, p. 179-208, 1991.

. Technical Change and Industrial Transformation: the theory and an application to the semiconductor industry. New York: St. Martin Press, 1984

Technological paradigms and technological trajectories: A suggested interpretation of the determinants and directions of technical change. Research Policy, Amsterdam, v. 11, n. 3, p. 147-162, Jun. 1982.

Dosi, G.; Nelson, R. R. Technical Change and Industrial Dynamics as Evolutionary Processes. In Hall, B.; Rosenberg, N. (Eds.). Handbook of the Economics of Innovation, Vol. 1. Amsterdam: Elsevier, 2010.

Doyle, S. The role of social networks in marketing. Database Marketing \& Customer Strategy Management, v. 15, n. 1, p. 60-64, 2007.

Edquist, C. The fixed Internet and mobile telecommunications sectoral system of innovation: equipment production, access provision and content provision. In: Malerba, F. (Ed.). Sectoral Systems of Innovation: Concepts, Issues and Analyses of Six Major Sectors in Europe. New York: Cambridge University Press, 2004.

Fligstein, N; Dauter, L. The Sociology of Markets. Annual Review of Sociology, Palo Alto, v. 33, p. 105-128, Aug. 2007.

Folha de S. Paulo. Sete em cada dez usuários de banda larga gostariam de trocar de operadora. Folha de S. Paulo, 18 jul. 2013. Available at http://www1.folha.uol.com.br/mercado/2013/07/1312785-sete-em-cada-dez-usuarios-de-banda-largagostariam-de-trocar-de-operadora.shtml. Access in 18 Jul. 2013.

Funk, J. L. The co-evolution of technology and methods of standard setting: the case of the mobile phone industry. Journal of Evolutionary Economics, Heidelberg, v. 19, n. 1, p. 73-93, Feb. 2009.

Gjoka, M.; Kurant, M.; Butts, C. T.; Markopoulou, Walking in Facebook: A Case Study of Unbiased Sampling of OSNs. 2010 Proceedings of IEEE INFOCOM '10, San Diego, 2010.

Gjoka, M.; Kurant, M.; Markopoulou, A. 2.5K-graphs: From sampling to generation. 2013 Proceedings on IEEE INFOCOM, Genève: IEEE, p. 1968-1976, 2013.

Godes, D.; Mayzlin, D. Using online conversations to study word-of-mouth communication. Marketing Science, v. 23, n. 4, p. 545-560, 2004.

Goyal, S. Connections: An Introduction to the Economics of Networks. Princeton: Princeton University Press, 2007.

Greenstein, S. The emergence of the Internet: collective invention and wild ducks. Industrial and Corporate Change, Oxford, v. 19, n. 5, p. 15211562, Oct. 2010.

Hodgson, G. M. Economics and Institutions, Philadelphia: University of Pennsylvania Press, 1988.

Hodgson, G. M.; Knudsen, T. The complex evolution of a simple traffic convention: the functions and implications of habit. Journal of Economic Behavior \& Organization, Amsterdam, v. 54, n. 1, p. 19-47, 2004.

ITU (International Telecommunications Union). Measuring the Information Society: 2013. Geneva: ITU, 2013.

ITU (International Telecommunications Union). World Telecommunication/ICT Indicators database 2014: 2014. Available at: http://www.itu.int/pub/D-IND-WTID.OL-2014. Access in 18 Dec. 2014.

Jonard, N.; Yildizoğlu, M. Technological diversity in an evolutionary industry model with localized learning and network externalities. Structural Change and Economic Dynamics, Amsterdam, v. 9, n. 1, p. 35-53, Mar. 1998.

Karnstedt, M.; Hennessy, T.; Chan, J.; Basuchowdhuri, P.; Hayes, C.; Strufe, T. Churn in Social Networks. In Furht, B. (Ed.). Handbook of Social Network Technologies and Applications. Boston: Springer, p. 185-220, 2010.

Kavassalis, P.; Solomon, R. J.; Benghozi, P. J. The Internet: a paradigmatic rupture in cumulative telecom evolution, Industrial and Corporate Change, Oxford, v. 5, n. 4, p. 1097-1126, 1996.

Kawale, J.; Pal, A.; Srivastava, J. Churn Prediction in MMORPGs: A Social Influence Based Approach. International Conference on Computational Science and Engineering, 2009. Annals...Vancouver: IEEE, $2009 . \quad$ Available at http://ieeexplore.ieee.org/lpdocs/epic03/wrapper.htm?arnumber=5284154. Access in 14 jun. 2014.

Kozinets, R. V.; Valck, K.; Wojnicki, A. C.; Wilner, S. J. S. Networked Narratives: Understanding Word-of-Mouth Marketing in Online Communities. Journal of Marketing, v. 74, n. 2, p. 71-89, May 2010.

Laffont, J.-J.; Rey, P.; Tirole, J. Network competition: Overview and nondiscriminatory pricing. RAND Journal of Economics, p. 1-37, 1998. . Internet interconnection and the off-net-cost pricing principle. RAND Journal of Economics, p. 370-390, 2003.

Mahadevan, P.; Krioukov, D.; Fall, K.; Vahdat, A. Systematic topology analysis and generation using degree correlations. Computer Communications Review, v. 36, p. 135, 2006.

Martin, W. C.; Lueg, J. E. Modeling word-of-mouth usage. Journal of Business Research, v. 66, p. 801-808, 2013.

Maxham, J.G. Service recovery's influence on consumer satisfaction, positive word-of-mouth, and purchase intentions. Journal of Business Research, v. 54, n. 1, p. 11-24, 2001.

Metcalfe, J. S. Evolutionary Economics and Creative Destruction. New York: Routledge, 1998. 153 p.

Morris, M. D. Factorial sampling plans for preliminary computational experiments. Technometrics, v. 33, n. 2, p. 161-174, 1991.

Nelson, R. R. Recent Evolutionary Theorizing About Economic Change, Journal of Economic Literature, Pittsburgh, v. 33, n. 1, p. 48-90, Mar. 1995. 
Nelson, R. R.; Sampat, B. Making sense of institutions as a factor shaping economic performance. Journal of Economic Behavior and Organization, v. 44, p. 31-54, 2001.

NOKIA SIEMENS NETWORKS. 2013 Acquisition \& Retention Study Report. Available at http://nsn.com/system/files/document/acquisition_retention_white_paper.pdf. Access on 03 Mar. 2014.

OECD (Organization for Economic Co-operation and Development). Broadband and telecom statistics. Available at: https://www.oecd.org/internet/broadband/. Access in 03 Feb. 2015.

OOKLA. Net Index Explorer. 2014. Available at: http://explorer.netindex.com. Access on: 04 out. 2014.

Ovum. Quality of mobile broadband the main reason for consumers to change provider. 2014. Available at http://www.ovum.com/press_releases/.

Access on 07 Nov. 2014

Orléan, A. Réflexion sur les fondements institutionnels de l'objectivité marchande. Cahiers d'Économie Politique, v. 44, n. 1, p. 181-196, 2003.

Pavitt, K. Sectoral patterns of technological change: Towards a taxonomy and a theory. Research Policy, Amsterdam, v. 13, n. 6, p. 343-374, Dec. 1984

Pereira, M. C.; Dequech, D. A history-friendly model of the internet access market: the case of Brazil. In: Pyka, A.; Foster, J. (Ed.). Economic Complexity and Evolution. Cham, Switzerland: Springer, p. 579-610, 2015.

Pereira, P.; Ribeiro, T. The impact on broadband access to the Internet of the dual ownership of telephone and cable networks. International Journal of Industrial Organization, Amsterdam, v. 29, n. 2, p. 283-293, Mar. 2011.

Powell, W. W.; Smith-Doerr, L. Networks and Economic Life. In Smelser, N.; Swedberg, R. (Eds.). The Handbook of Economic Sociology. Princeton: Princeton University Press, p. 368-425, 2004.

R Core Team. R: A Language and Environment for Statistical Computing. R Foundation for Statistical Computing. Vienna, Austria. Available at https://www.Rproject.org/. Access in 2016.

Rogers, E. M. Diffusion of innovations, 4e. New York: Free Press, 2010.

Sala, A.; Cao, L.; Wilson, C.; Zablit, R.; Zheng, H.; Zhao, B. Measurement-calibrated graph models for social network experiments. Proceedings of the 19th international conference on World Wide Web., New York: ACM, p. 861-870, 2010.

Salle, I.; Yildizoğlu, M. Efficient Sampling and Meta-Modeling for Computational Economic Models. Computational Economics, v. 44, n. 4, p. 507-536, 2014.

Saltelli, A.; Annoni, P. How to avoid a perfunctory sensitivity analysis. Environmental Modelling \& Software, v. 25, n. 12, p. 1508-1517, 2010.

Saltelli, A.; Ratto, M.; Andres, T.; Campolongo, F.; Cariboni, J.; Gatelli, D.; Tarantola, S. Global sensitivity analysis: the primer. John Wiley \& Sons, 2008.

Saviotti, P. P. Knowledge Networks: Structure and Dynamics. In Pyka, A.; Scharnhorst, A. (Eds.). Innovation Networks: Understanding Complex Systems, Berlin: Springer, 2009.

Scheller, F. Por que o brasileiro gosta tanto de marcas. Estado de S. Paulo, São Paulo, ago. 2012. Available at http://economia.estadao.com.br/noticias/geral,por-que-o-brasileiro-gosta-tanto-de-marcas-imp-,911841. Access on 06 Aug. 2012.

Schmidt, S.; Missler-Behr, M. Importance of consumer preferences on the diffusion of complex products and systems. In: Classification as a Tool for Research. Springer Berlin Heidelberg. p. 725-733, 2010.

SEAE (Secretaria de Acompanhamento Econômico - Ministério da Fazenda); SDE (Secretaria de Direito Econômico - Ministério da Justiça). Guia para análise econômica de atos de Concentração horizontal. Portaria Conjunta SEAE/SDE n. 50, Brasília, 1 Aug. 2001.

SEPIN (Secretaria de Política de Informática e Automação - Ministério da Ciência e Tecnologia). Evolução da Internet no Brasil e no Mundo. Mimeo, Brasília, 2000.

Shapiro, C.; Varian, H. R. (1999). A economia da informação: como os princípios econômicos se aplicam a era da internet. 5. ed. Rio de Janeiro: Campus, 2002.

Shy, O. The economics of network industries. Cambridge: Cambridge Univ. Press, 2001.

Sobol', I. M. Sensitivity analysis for non-linear mathematical models. Mathematical Modelling and Computational Experiments, 407-414, 1993.

Stigler, G. J.; Becker, G. S. De gustibus non est disputandum. American Economic Review, v. 67, n. 2, p. 76-90, 1977.

Sweeney, J.C. ; Soutar, G.N.; Mazzarol, T. Factors influencing word of mouth effectiveness: receiver perspectives. European Journal of Marketing, v. 42, n. 3/4, p. 344-364, 2008.

TELEBRASIL (Associação Brasileira de Telecomunicações). O Desempenho do Setor de Telecomunicações no Brasil - Séries Temporais: primeiro semestre de 2014. Rio de Janeiro: TELEBRASIL, 2014.

Tolbert, P. S.; Zucker, L. G. The Institutionalization of Institutional Theory. In Clegg, S. R.; Hardy, C.; Nord, W. R. (Ed.). Handbook of Organization Studies, Thousand Oaks: Sage, 1996.

Ugander, J.; Karrer, B.; Backstrom, L.; Marlow, C. The Anatomy of the Facebook Social Graph. arXiv, preprint arXiv,1111.4503, 2011.

United States Department of Justice. Herfindahl-Hirschman Index. Available at https://www.justice.gov/atr/herfindahl-hirschman-index. Access on 13 Dec. 2015.

Valente, M. Evolutionary demand: a model for boundedly rational consumers. Journal of Evolutionary Economics, v. 22, n. 5, p. 1029-1080, 2012.

Valente, M. LSD: Laboratory for Simulation Development. University of L'Aquila. L'Aquila, Italy. Available at https://www.labsimdev.org/. Access on 12 May 2016

Varian, H. R. The demand for bandwidth: Evidence from the INDEX project. Broadband: should we regulate high-speed Internet access, p. 3956,2002

Viscusi, W. K.; Harrington JR., J. E.; Vernon, J. M. Economics of Regulation and Antitrust. 4 ed. Cambridge: MIT Press, 2005.

Viswanath, B.; Mislove, A.; Cha, M.; Gummadi, K.P. On the evolution of user interaction in Facebook. Proceedings of the 2nd ACM workshop on Online Social Networks, 2009.

Wilson, C.; Boe, B.; Sala, A.; Puttaswamy, K. P.; Zhao, B. Y. User interactions in social networks and their implications. In Proceedings of the 4th ACM European conference on Computer systems, p. 205-218, 2009.

Yang, J.; He, X.; Lee, H. Social reference group influence on mobile phone purchasing behaviour: a cross-nation comparative study. Int. $J$. Mobile Communications, v. 5, n. 3, p. 319-338, 2007. 